\title{
A broader role for AmyR in Aspergillus niger: regulation of the utilisation of D-glucose or D-galactose containing oligo- and polysaccharides
}

\author{
Patricia A. vanKuyk • Jaques A. E. Benen • \\ Han A. B. Wösten • Jaap Visser • Ronald P. de Vries
}

Received: 19 May 2011 /Revised: 6 August 2011 / Accepted: 13 August 2011 / Published online: 27 August 2011

(C) The Author(s) 2011. This article is published with open access at Springerlink.com

\begin{abstract}
AmyR is commonly considered a regulator of starch degradation whose activity is induced by the presence of maltose, the disaccharide building block of starch. In this study, we demonstrate that the role of AmyR extends beyond starch degradation. Enzyme activity assays, genes expression analysis and growth profiling on D-glucose- and D-galactose-containing oligoand polysaccharides showed that AmyR regulates the expression of some of the Aspergillus niger genes
\end{abstract}

Electronic supplementary material The online version of this article (doi:10.1007/s00253-011-3550-6) contains supplementary material, which is available to authorized users.

P. A. vanKuyk · J. A. E. Benen · J. Visser

Molecular Genetics of Industrial Microorganisms,

Wageningen University,

Dreijenlaan 2,

6703 HA Wageningen, The Netherlands

P. A. vanKuyk

Molecular Microbiology, Leiden University,

Sylviusweg 72,

2333 BE Leiden, The Netherlands

H. A. B. Wösten • R. P. de Vries

Microbiology and Kluyver Centre for Genomics

of Industrial Fermentation, Utrecht University,

Padualaan 8 ,

$3584 \mathrm{CH}$ Utrecht, The Netherlands

R. P. de Vries $(\bowtie)$

CBS-KNAW Fungal Biodiversity Centre,

Uppsalalaan 8,

3584 CT Utrecht, The Netherlands

e-mail: r.devries@cbs.knaw.nl

Present Address:

J. Visser

Fungal Genetics and Technology Consultancy,

P.O. Box 396, 6700 AJ Wageningen, The Netherlands encoding $\alpha$ - and $\beta$-glucosidases, $\alpha$ - and $\beta$-galactosidases, as well as genes encoding $\alpha$-amlyases and glucoamylases. In addition, we provide evidence that D-glucose or a metabolic product thereof may be the inducer of the AmyR system in A. niger and not maltose, as is commonly assumed.

Keywords Aspergillus niger AmyR · Polysaccharide degradation Gene regulation

\section{Introduction}

AmyR was the first transcriptional activator of the GAL4 type identified in filamentous fungi that is involved in the degradation of plant polysaccharides (Petersen et al. 1999). Its role in starch degradation has been studied in detail in different Aspergillus species, such as Aspergillus nidulans and Aspergillus oryzae, and AmyR was shown to activate expression of glucoamylase, $\alpha$-amylase and $\alpha$-glucosidase in the presence of starch or maltose (Gomi et al. 2000; Petersen et al. 1999; Tani et al. 2001). The amylolytic system has also been studied in Aspergillus niger, and a recent study compared the expression of genes related to starch degradation using micro-array analysis (Yuan et al. 2008) but did not study in detail other genes that may be under AmyR control.

Induction of the amylolytic system in Aspergillus is reported to be caused by the presence of starch or its disaccharide building block, maltose (Barton et al. 1972; Carlsen and Nielsen 2001; Pedersen et al. 2000; Santerre Henriksen et al. 1999), and the latter compound is often suggested to be the low-molecular-weight inducer of the system. However, the actual nature of the inducer has not been studied in detail. It has also been claimed that 
iso-maltose is the inducing compounds (Kato et al. 2002), but no conclusive evidence has been presented to verify this. D-glucose has been shown to repress the expression of the amylolytic genes (Tsukagoshi et al. 2001) but was also reported as an inducer for the amylolytic genes of A. oryzae (Carlsen and Nielsen 2001). However, no studies have been reported in which low levels of D-glucose were tested for induction of the amylolytic system in Aspergillus.

A role in both induction and repression has been observed previously for D-xylose and the xylanolytic system of A. niger (de Vries et al. 1999b). In this fungus, D-xylose induces the xylanolytic regulator $\mathrm{X} \operatorname{lnR}$ that activates expression of xylanolytic and cellulolytic genes. The concentration of D-xylose in the medium affects the expression level of the genes. High D-xylose concentrations result in activation of the carbon catabolite repressor protein CreA that represses the expression of the XlnR-regulated genes.

Although $\mathrm{X} \ln \mathrm{R}$ was originally described as a xylanolytic activator, later studies indicated that it also controlled genes that were not involved in xylan degradation and utilization. These genes encoded enzymes involved in cellulose, xyloglucan and galactomannan degradation (de Vries et al. 1999a; Gielkens et al. 1999; Hasper et al. 2002).

Here, we present a study into the A. niger amyR gene in which we constructed deletion and multicopy strains. Using these strains, we have found that D-glucose induces the amylolytic system depending on the concentration in the medium. In addition, it became clear that AmyR has a broader physiological role than starch degradation in that it controls the production of D-glucose and D-galactose releasing enzymes.

\section{Materials and methods}

Strains and media

All A. niger strains used are derivatives of N402 (FGSC A733; Table 1). Inocula for shake flask cultivations were obtained from cultures grown on complete medium agar plates (de Vries et al. 2004). Minimal medium (MM; de Vries et al. 2004) was inoculated with harvested conidia to give a concentration of $1.0 \times 10^{6}$ conidia per milliliter. Supplements to complement the auxotrophic requirements were added when required and were $200 \mathrm{mg} / \mathrm{l}$ leucine, $122 \mathrm{mg} / \mathrm{l}$ uridine and $1 \mathrm{mg} / \mathrm{l}$ nicotinic acid (niacin). The liquid pre-cultures contained $2 \% \mathrm{D}$-fructose as the sole carbon source. Sugars were not autoclaved but filtersterilised and added to the autoclaved medium. Maltose, Dglucose (G8270, 99.5\%), D-fructose, lactose and D-xylose were from Sigma. Soluble starch was from Difco. Cultures were grown at $30^{\circ} \mathrm{C}$, with $250 \mathrm{rpm}$ rotary shaking. Precultures were cultivated for $16 \mathrm{~h}$, mycelia were washed with MM (without carbon source), and $1.5 \mathrm{~g}$ wet weight filamentous mycelium was transferred to shake flasks containing $70 \mathrm{ml} \mathrm{MM}$ with the carbon sources, as stated in the results. Transferred mycelium was then incubated at $30^{\circ} \mathrm{C}$ with $250 \mathrm{rpm}$ rotary shaking for $2-24 \mathrm{~h}$ (see "Results" for details of specific experiments) before mycelia were harvested and/or culture filtrate samples taken. A. niger transformations were performed as described previously (Kusters-van Someren et al. 1991).

Molecular methods

DNA manipulations and molecular biology techniques were performed using standard methods (Sambrook et al. 1989) and Escherichia coli DH5 $\alpha$. Gel extractions were performed using the QIAgen QIAquick gel extraction kit.

RNA analysis was performed as described previously (de Vries et al. 2002). Internal fragments of lacA (A00968, An01g12150; Kumar et al. 1992), aglC (AJ251873, An09g00260/270; Ademark et al. 2001), $\operatorname{agdA}$ (An04g06920; Pel et al. 2007), glaA (X00548, An03g06550; Boel et al. 1984), amyA (An04g06930) and amyR (An04g06910; Pel et al. 2007) were used as probes for expression analysis. A $0.7-\mathrm{kb}$ EcoRI fragment from the gene encoding the 18S rRNA subunit (Melchers et al. 1994) was used as an RNA loading control.

\section{Sequence analysis}

Nucleotide sequences were analysed with computer programs based on those of Devereux et al. (Devereux et al. 1984). Sequence alignments were performed by using the Blast programs (Altschul et al. 1990) at the server of the National Center for Biotechnology Information, Bethesda, USA (http://www.ncbi.nlm.nih.gov/blast/). Synteny analysis was performed at the AspGD website (http://www.aspgd.org/) using the Sybil programme.

\section{Enzyme assays}

Extracellular hydrolytic activities were assayed using $0.01 \%$ substrate, $20-40 \mu \mathrm{l}$ sample and $25 \mathrm{mM}$ sodium acetate $\mathrm{pH} 5.0$ in a total volume of $100 \mu \mathrm{l}$. The mixtures were incubated for $1 \mathrm{~h}$ at $30^{\circ} \mathrm{C}$ after which the reaction was stopped by adding $100 \quad \mu 1 \quad 0.25 \quad \mathrm{M} \mathrm{Na}_{2} \mathrm{CO}_{3}$. Absorbance was measured at $405 \mathrm{~nm}$ in a microtiter plate reader. The activity was calculated using a standard curve of $p$-nitrophenol. The substrates used for enzyme assays were all obtained from Sigma and were $p$-nitrophenol$\alpha$-arabinofuranoside, $p$-nitrophenol- $\alpha$-xylopyranoside, $p$ nitrophenol- $\beta$-xylopyranoside, $p$-nitrophenol- $\alpha$-galactopyra- 
Table 1 A. niger strains used in this study

\begin{tabular}{|c|c|c|}
\hline Strain & Genotype & Reference \\
\hline N402 & $\operatorname{csp} A 1$ & Bos et al. (1988) \\
\hline NW249 & $\Delta \arg B$, pyrA6, leuA1, nicAl & vanKuyk et al. (2004) \\
\hline UU-A049.1 & $\triangle \arg B, \operatorname{pyr} A 6, \operatorname{leu} A 1$, nicA1, $\arg B^{+}$ & This study \\
\hline UU-A101.1 & $\triangle \arg B, \operatorname{pyr} A 6, l e u A 1$, nicAl, $\triangle \operatorname{amy} R:: \arg B^{+}$ & This study \\
\hline UU-A001.13 & $\triangle \arg B, \operatorname{pyr} A 6, l e u A 1$, nicAl, $\arg B^{+}$, mcamy $R$ & This study \\
\hline UU-A001.24 & $\arg B \Delta$, pyrA6, leuA1, nicAl, $\arg B^{+}$, mcamyR & This study \\
\hline
\end{tabular}

noside, $p$-nitrophenol- $\beta$-galactopyranoside, $p$-nitrophenol$\alpha$-glucopyranoside, $p$-nitrophenol- $\beta$-glucopyranoside, $p$ nitrophenol- $\alpha$-fucopyranoside, $p$-nitrophenol- $\beta$-fucopyranoside, $p$-nitrophenol- $\beta$-glucuronoside and $p$-nitrophenol$\beta$-mannopyranoside to measure $\alpha$-arabinofuranosidase, $\alpha$ - and $\beta$-xylosidase, $\alpha$ - and $\beta$-galactosidase, $\alpha$ - and $\beta$-glucosidase, $\beta$-glucuronidase and $\beta$-mannosidase, respectively.

\section{Results}

Identification and cloning of amyR

A lambda phage clone was isolated from an $A$. niger gDNA library using a fragment of the $A$. oryzae amy $R$ gene as a probe. A 4.3-kb $N s i$ I fragment was subcloned into pGEM-11 and designated pJG01. Sequence analysis showed that this fragment contained the coding region of $A$. niger amy $R$ as well as the $5^{\prime}$-flanking region and part of the $A$. niger agdA gene. Further analysis using the Sybil tool at www.aspgd.org (Crabtree et al. 2007) demonstrated that the amylolytic cluster (amyA-aglA-amyR) is highly conserved in all eight sequenced Aspergilli, with only a small insertion downstream of amyR in Aspergillus terreus (Suppl. Fig. 1). In all these species except $A$. nidulans, the proteolytic regulator PrtT (Punt et al. 2008) lies directly upstream from the cluster.

Construction and analysis of disruption and multicopy amyR strains

A deletion construct (pAmyRd) was made by introducing a PstI site 800 bp downstream of the endogenous PstI site of pJG01. Plasmid pJG01 was then digested with BamHI/NsiI and the liberated fragment cloned into pGEM9. The resulting construct (pJG10) was digested with $P s t \mathrm{I} /$ BamHI, and a $B g l \mathrm{II} / P s t \mathrm{I}$ fragment containing the $\arg B$ gene of $A$. niger was inserted. Insertion of this construct at the $a m y R$ locus would result in the removal of $1,600 \mathrm{bp}$, consisting of approximately $600 \mathrm{bp} 5$ '-region and 1,000 bp coding region (including the zinc finger). This fragment was used to transform $A$. niger NW249. In addition, pJG01 was used in a co-transformation with pIM2101 (containing the $A$. niger $\arg B$ gene (Lenouvel et al. 2002)) to obtain $a m y R$ multicopy strains in $A$. niger NW249. Transformants were screened for their ability to grow on starch. Selected transformants from the disruption transformation with reduced growth and from the multicopy transformation with improved growth on starch were used for Southern analysis and demonstrated that multiple disruption and multicopy transformants were obtained (data not shown). Based on this analysis, UU-A001.24 was selected as amyR multicopy (overexpression) transformant and UU-A101.1 was selected as an amyR disruptant.

The influence of AmyR extends beyond amylolytic genes

Strains UU-A001.24 (amyR overexpression) and UUA101.1 (amyR disruptant) together with UU-A049.1 (reference strain) were grown overnight in complete medium (CM) with 2\% fructose and transferred to MM with the carbon sources indicated in Fig. 1 for $6 \mathrm{~h}$. Culture filtrate samples were used to determine the presence of extracellular enzymes. No activity was detected on any of the carbon sources for $\alpha$ - or $\beta$ fucosidase, $\alpha$-xylosidase, $\alpha$-arabinofuranosidase, $\beta$ mannosidase or $\beta$-glucuronidase (data not shown). However, $\alpha$ - and $\beta$-galactosidase and $\alpha$ - and $\beta$-glucosidase activity were detected on D-glucose, lactose, maltose and starch (Fig. 1). Compared with the reference strain (UU-A049.1), these activities were lower in the $a m y R$ disruptant and 2- to 15-fold increased in the $a m y R$ multicopy strain.

Based on recent $A$. niger genome annotations (Coutinho et al. 2009; Pel et al. 2007), genes encoding $\alpha$-amylase (AMY), glucoamylase (GLA), $\alpha$-glucosidase (AGD), $\beta$ glucosidase (BGL), $\alpha$-galactosidase (AGL) and $\beta$ galactosidase (LAC) were analysed for their expression in an $A$. niger wild-type and amyR disruptant on maltose using previously published micro-array data (Yuan et al. 2008). This demonstrated that AmyR controls only a small subset of these genes (Suppl. Table 1), but this subset included two BGL-, two AMY-, two AGD-, two GLA-, two AGL and one LAC-encoding genes, supporting the activity assays performed in our study. All these genes contained at least one putative AmyR binding site in their promoter. 
A

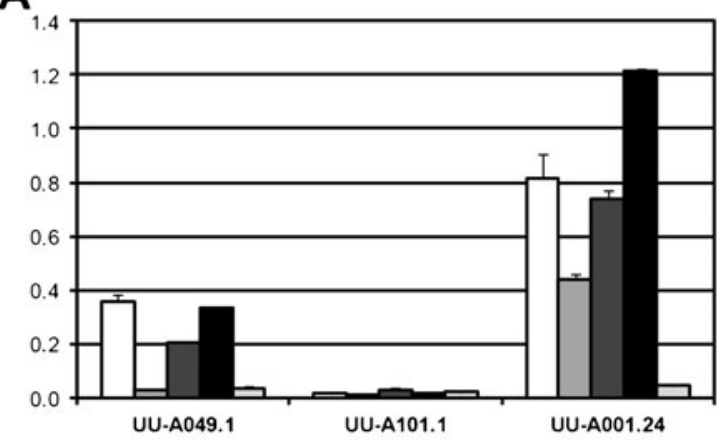

B

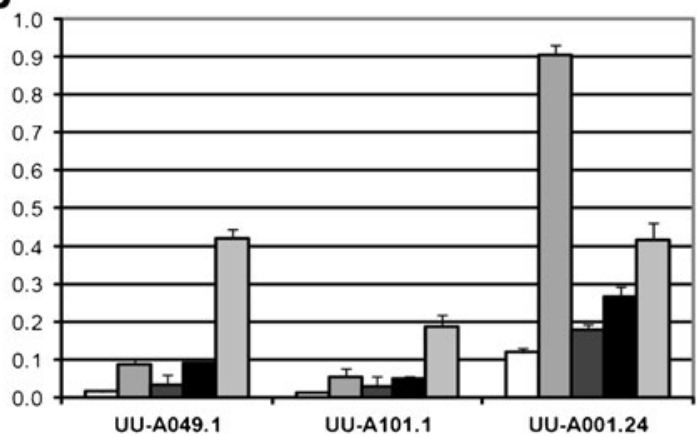

C

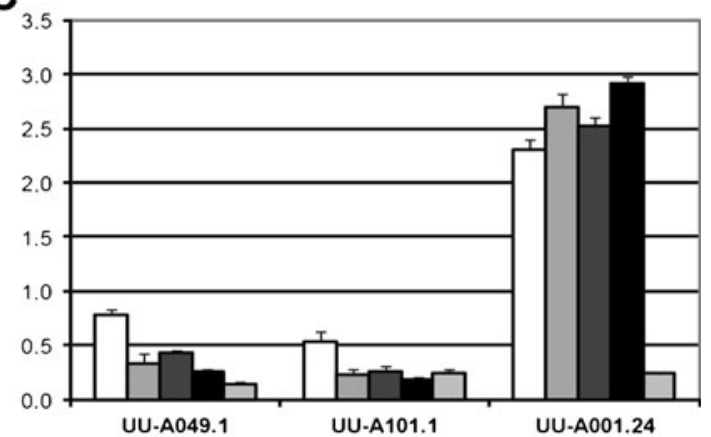

D

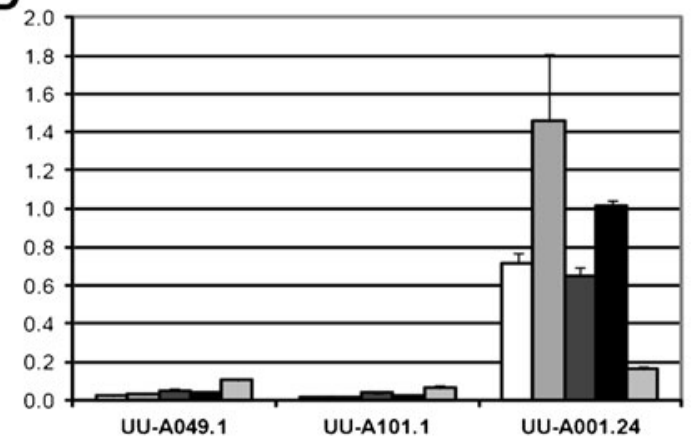

E

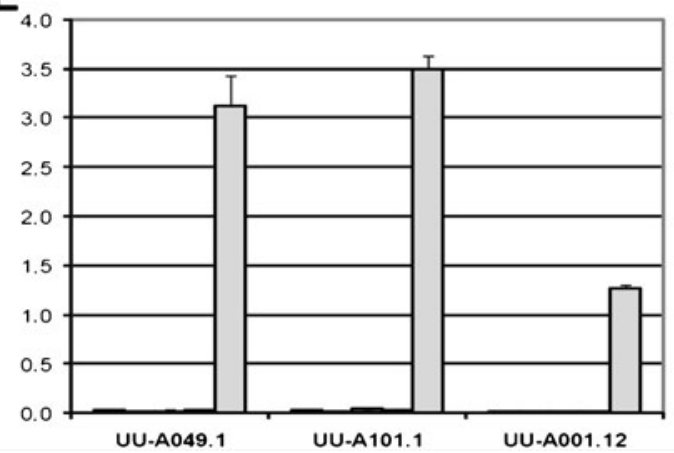

\begin{tabular}{|l|}
\hline Glucose \\
$\square$ Lactose \\
$\square$ Maltose \\
Starch \\
$\square$ Xylose \\
\hline
\end{tabular}

Fig. 1 Extracellular activities in UU-A049.1 (reference strain), UUA101.1 ( $\triangle a m y R)$ and UU-A001.24 (amyR multicopy strain) on five carbon sources ( $25 \mathrm{mM}$ for mono- and disaccharides, $1 \%$ for starch). Activity (nanomoles per minute per milliliter culture filtrate) was assayed in culture filtrates obtained $6 \mathrm{~h}$ after transfer. Enzyme activities measured were $\mathbf{A} \alpha$-glucosidase (AGD), $\mathbf{B} \beta$-glucosidase (BGL), $\mathbf{C} \alpha$-galactosidase (AGL), $\mathbf{D} \beta$-galactosidase (LAC), and (E) $\beta$-xylosidase (BXL)
To confirm these data, a transfer experiment was performed in which UU-A049.1, UU-A001.24 and UUA101.1 were pre-grown $\mathrm{O} / \mathrm{N}$ in $\mathrm{CM}$ with $2 \%$ fructose. Mycelial aliquots were transferred to $25 \mathrm{mM}$ D-glucose, $25 \mathrm{mM}$ maltose and $1 \%$ starch and incubated for the time points indicated in Fig. 2. Northern analysis was performed for the three genes of the AmyR cluster $(\operatorname{amy} R, \operatorname{agd} A, \operatorname{amy} A)$, the main glucoamylase $(g l a A)$ and genes encoding an $\alpha$-galactosidase ( $a g l C$; Ademark et al. 2001) and a $\beta$-galactosidase (lacA; de Vries et al. 1999a; Kumar et al. 1992). Expression of glaA, amyA and agdA on maltose and starch was reduced in the amyR disruption strain (UU-A101.1) and increased in the amyR multicopy strain (UU-A001.24; Fig. 2). A similar effect was observed for $\operatorname{lacA}$ and $a g l C$, although the expression of the genes peaked at the latest and earliest timepoint, respectively.

A similar expression pattern was observed for glaA, $\operatorname{agdA}$ and amyA on D-glucose, and expression was highest at the latest time point (Fig. 2). Expression of $a g l C$ and $l a c A$ was not reduced in the $a m y R$ disruptant compared to the reference on D-glucose but was increased in the $a m y R$ multicopy strain. 


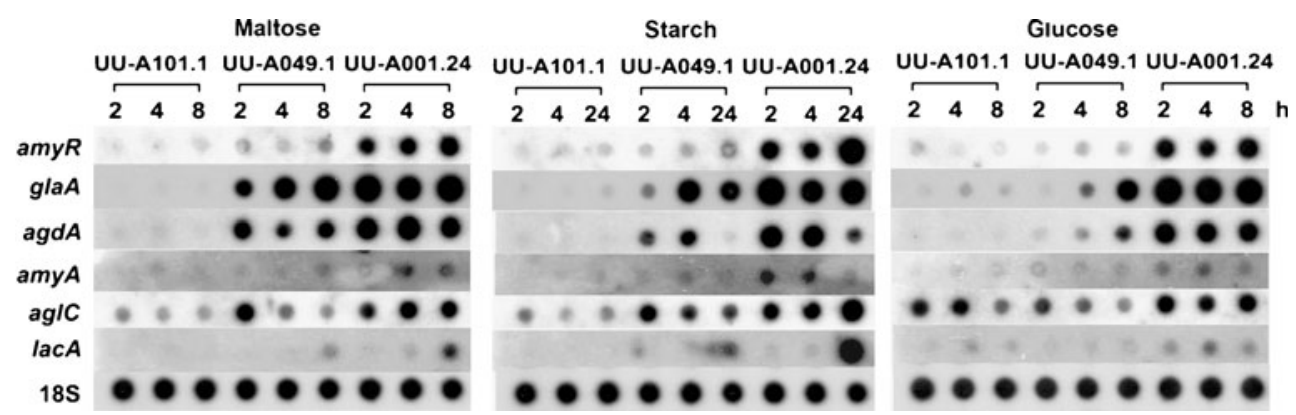

Fig. 2 Expression analysis of amyR (amylolytic activator), glaA (glucoamylase), agdA ( $\alpha$-glucosidase), amyA ( $\alpha$-amylase), aglC $(\alpha-$ galactosidase) and lacA ( $\beta$-galactosidase) in UU-A049.1 (ref), UU-

Influence of AmyR on growth of A. niger on oligo- and polysaccharides

To study the physiological effect of this putative broader role for AmyR, a growth experiment was performed using UU-A049.1, UU-A001.24 and UU-A101.1 on a variety of carbon sources, including controls (xylose, D-glucose) and several oligo- and polysaccharides containing $\alpha$ - or $\beta$ linked D-glucose or D-galactose residues (Fig. 3). Reduced growth was observed for the amyR disruptant (UU-A101.1) on maltose, starch, lactose, melibiose, raffinose, melezitose and carrageenan compared with the reference strain (UU-A049.1). No clearly improved growth could be seen on most of these substrates for the amyR multicopy strain (UUA001.24), with the exception of lactose, where some increase in vegetative growth was visible, but especially a significant increase in sporulation was observed. Growth and, in particular, sporulation of the reference strain and the $a m y R$ multicopy strain on carrageenan was poor on these substrates. No increase in sporulation was observed in the $a m y R$ multicopy strain compared with the reference strain.

No difference in growth was observed between the strains using sucrose, D-xylose or D-glucose as a carbon source and only a slight reduction in growth of the amyR disruptant on cellobiose and Guar gum. Furthermore, no difference in growth was observed on chitin, $\mathrm{N}$-acetylglucosamine and inulin (data not shown).

Increased concentrations of D-glucose results in altered morphology in amyR multicopy strains

Early in the growth experiments, an unusual morphology (dense colonies with reduced sporulation) was observed for the amyR multicopy strain on maltose and starch. In this strain, it can be expected that maltose is very quickly converted extracellularly to D-glucose by the overproduction of glucoamylase, and therefore a second growth experiment was performed at different D-glucose concentrations to determine whether this morphology was indeed caused by the D-glucose level. The reference (UU-A049.1)
A101.1 ( $\triangle a m y R)$ and UU-A001.24 (amyR multicopy strain) during growth on $25 \mathrm{mM}$ maltose, $1 \%$ starch and $25 \mathrm{mM}$ D-glucose at various time points (in hours)

and two multicopy strains (UU-A001.24 and UU-A001.13; a second multicopy strain was included to verify that this is a general effect) were grown on MM plates with D-glucose ranging from 0.5 to $400 \mathrm{mM}$. No significant difference was observed between the strains at D-glucose concentration of $25 \mathrm{mM}$ or lower. At $50 \mathrm{mM}$, a small difference can be observed in that the mycelium of the amyR multicopy strains is denser. At $100 \mathrm{mM}$ and higher, the same morphology is observed as seen for maltose in the multicopy strains: dense mycelium and reduced sporulation (Fig. 4).

\section{Discussion}

AmyR has been studied in detail in several Aspergilli, with emphasis on genes involved in starch and maltose hydrolysis, although a recent study (Yuan et al. 2008) already indicated that other genes may also be controlled by AmyR. Analysis of enzyme activity in our study provided clear indications for a broader role of this regulator, in that we observed strongly elevated levels of both $\alpha$ - and $\beta$-glucosidase as well as $\alpha$ - and $\beta$ galactosidase in the amy $R$ multicopy strain compared with the reference. The reduction in enzyme activity in the $a m y R$ deletion strain was less obvious, possibly due to the fact that the activities in the reference were already very low. Analysis of publicly available micro-array data of an $A$. niger wild-type and amyR disruptant during growth on maltose (Yuan et al. 2008) demonstrated that some, but not all genes encoding these enzymes (Coutinho et al. 2009), were downregulated in the disruptant strain, suggesting regulation by AmyR. All the downregulated genes contained at least one putative AmyR binding site, which would be a pre-requisite for direct AmyR regulation. For one putative $\alpha$-galactosidase encoding gene (An04g02700), no putative AmyR binding site was identified in the DSM genome strain (CBS 513.88) (Coutinho et al. 2009). However, a putative binding site was detected in the genome of $A$. niger ATCC 1015 that was sequenced by JGI (Andersen et al. 2011). As we used the 
Fig. 3 Growth profiles of UU-A049.1 (reference strain), UU-A101.1 $(\triangle a m y R)$ and UU-A001.24 (amyR multicopy strain) on a variety of carbon sources. Carbon source concentrations were $25 \mathrm{mM}$ monosaccharides (D-glucose, D-xylose), $12.5 \mathrm{mM}$ disaccharides (maltose, sucrose, lactose, cellobiose, melibiose), $7.57 \mathrm{mM}$ trisaccharides (raffinose, melezitose), $1 \%$ polysaccharides (starch, carrageenan)

laboratory strain $\mathrm{N} 402$, this result suggests that this strain resembles ATCC 1015 with respect to the promoter of this gene. A similar difference was observed previously for the acetyl xylan esterase encoding gene axeA (R.P. de Vries, unpublished data). In both N402 and ATCC 1015, the promoter of this gene contains an XlnR consensus sequence, while CBS 513.88 does not. Also, several of the genes whose expression is not affected in the amy $R$ disruption strain contain putative AmyR binding sites in their promoter. This confirms that the presence of such a sequence is no direct indication for regulation by AmyR, as was concluded previously for AmyR, XlnR and other regulators of Aspergillus (Coutinho et al. 2009). However, the absence of such binding sites strongly suggests that the gene is not (directly) regulated.

These data were confirmed for one $\alpha$-galactosidase encoding gene $(a g l C)$ and one $\beta$-galactosidase encoding gene (lacA) using Northern analysis. On maltose and starch these two genes followed a similar pattern as the established AmyR regulated genes glaA, amyA and agdA. However, some differences were observed. The expression of lacA was only observed at late time points $(8 \mathrm{~h}$ on maltose and $24 \mathrm{~h}$ on starch), while aglC expression peaked at $2 \mathrm{~h}$, and the other genes were expressed on all time points. The reduced expression of $a g l C$ at later time points is not due to a reduction in expression compared with the pre-culture, as micro-array data from another study (R.P. de Vries, unpublished results) demonstrates lower aglC expression for the pre-culture than after $2 \mathrm{~h}$ on maltose or glucose. The expression of aglC in the amyR deletion strain was higher than that observed for the other genes tested, suggesting an AmyR-independent induction of $a g l C$. Expression of $a g l C$ on D-glucose was observed previously (Ademark et al. 2001) and was shown to be independent of the major carbon catabolite repression system CreA (Ruijter and Visser 1997) while D-galactose induction of this gene was not observed (Ademark et al. 2001).

Expression of $a g d A$ in the reference strain on glucose was only observed after prolonged incubation, which correlates well with detectable $\alpha$-glucosidase activity during growth of this strain on glucose as these activities were measured after $6 \mathrm{~h}$. The activity level is higher than expected based on the expression of agdA, but this is likely due to the presence of additional $\alpha$-glucosidases in the medium that are also produced under this condition.

Regulation of $\alpha$ - and $\beta$-glucosidase and $\alpha$ - and $\beta$ galactosidase activity by AmyR was further supported by growth profiling. Reduced growth of the amyR deletion

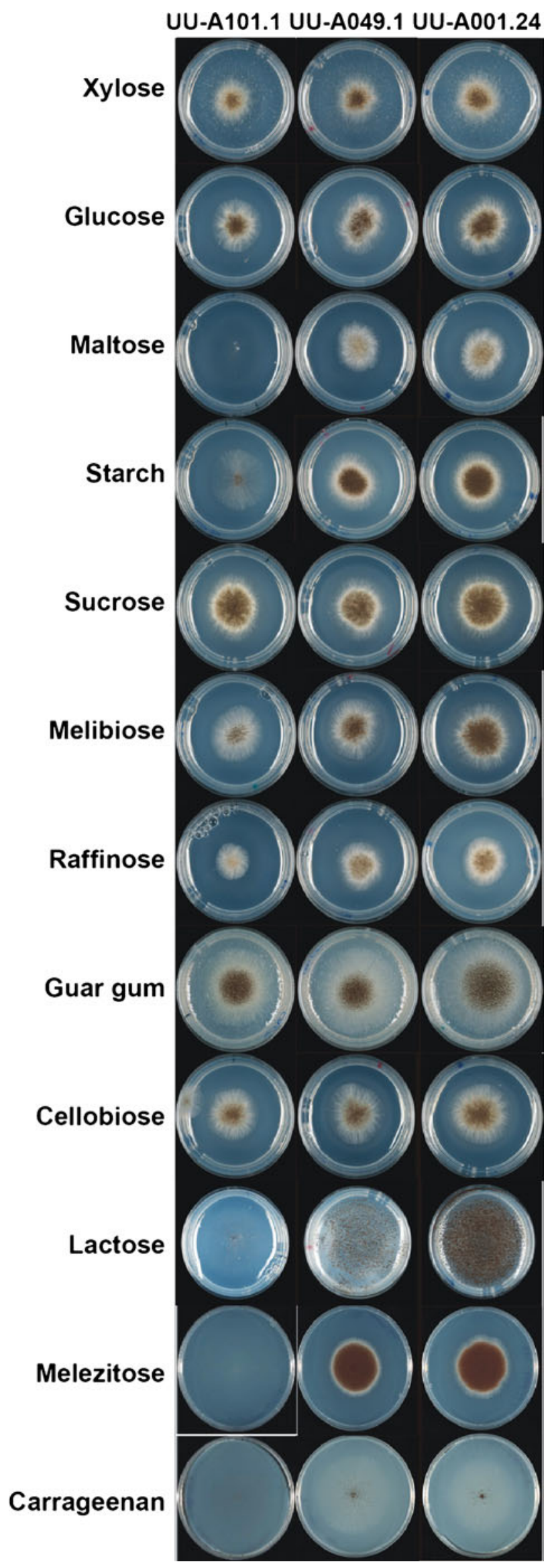


Fig. 4 Growth differences of UU-A049.1 (reference strain), and UU-A001.13 and UU-A001.24 (amyR multicopy strains) on different concentrations of D-glucose (Glc). Maltose (Malt) is included at the top of the figure for comparison

strain compared with the reference was observed on substrates containing $\alpha-$ (starch, maltose, melibiose, melezitose, raffinose, sucrose) and $\beta$-linked D-glucose (cellobiose) as well as $\alpha$ - (melibiose, raffinose, carrageenan) and $\beta$-linked D-galactose (lactose, carrageenan), while improved growth on several of these substrates was observed for the amyR multicopy strain. This provides in vivo evidence for a function for AmyR in utilization of these oligo- and polysaccharides by $A$. niger. This situation is similar to that for another Aspergillus transcriptional regulator related to polysaccharide degradation: XlnR. This protein was first described as a xylanolytic regulator (van Peij et al. 1998b) but was later shown to also regulate genes involved in cellulose degradation (van Peij et al. 1998a) and galactomannan degradation (de Vries et al. 1999a).

Several reports have provided evidence for different inducing compounds of the amylolytic system in Aspergillus. Most commonly, maltose is suggested to be the inducer of AmyR (Barton et al. 1972; Carlsen and Nielsen 2001; Pedersen et al. 2000; Santerre Henriksen et al. 1999), but also glucose (Carlsen and Nielsen 2001). Another study claimed that the inducer is iso-maltose (Kato et al. 2002), but a conclusive study has so far not been published. A. niger has been shown to produce high levels of glucoamylase in the presence of maltose or starch (Barton et al. 1972; Gouka et al. 1997a, b; Pedersen et al. 2000; Schrickx et al. 1995). In natural biotopes, high levels of maltose are uncommon, and it is therefore unlikely that the maltose liberated by $A$. niger during hydrolysis of starch is able to avoid the high levels of glucoamylase and get imported into the cell. It is more likely that (nearly) all maltose is hydrolysed extracellularly to D-glucose. Our study demonstrates that AmyR-regulated genes in A. niger are induced during growth on low levels of D-glucose, as their expression increases during the cultivation, which is similar to what was shown previously in A. oryzae (Carlsen and Nielsen 2001). As D-glucose has been shown to act as a repressor through the carbon catabolite repressor protein CreA (Ruijter and Visser 1997), the expression levels are likely a balance between induction through AmyR and repression through CreA. A previous study showed a similar effect for D-xylose and XlnR, in which higher D-xylose concentrations resulted in reduced expression of xylanolytic genes, mediated by CreA (de Vries et al. 1999b). In most studies reported previously (reviewed in Tsukagoshi et al. 2001), D-glucose is considered a repressing rather than an inducing carbon source. However, usually $1-3 \%$ (67-200 $\mathrm{mM})$ of D-glucose is used in these studies, which are concentrations at which the repression through

UU-A049.1 UU-A001.13 UU-A001.24

$25 \mathrm{mM}$ Malt

$0.5 \mathrm{mM}$ GIc

$1 \mathrm{mM}$ Glc

$10 \mathrm{mM} \mathrm{Glc}$

25 mM GIc

$50 \mathrm{mM}$ Glc

100 mM Glc

200 mM GIc

300 mM Glc

400 mM Glc
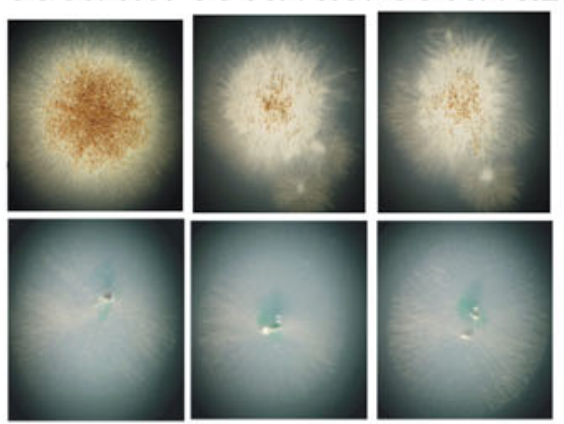

$5 \mathrm{mM}$ Glc
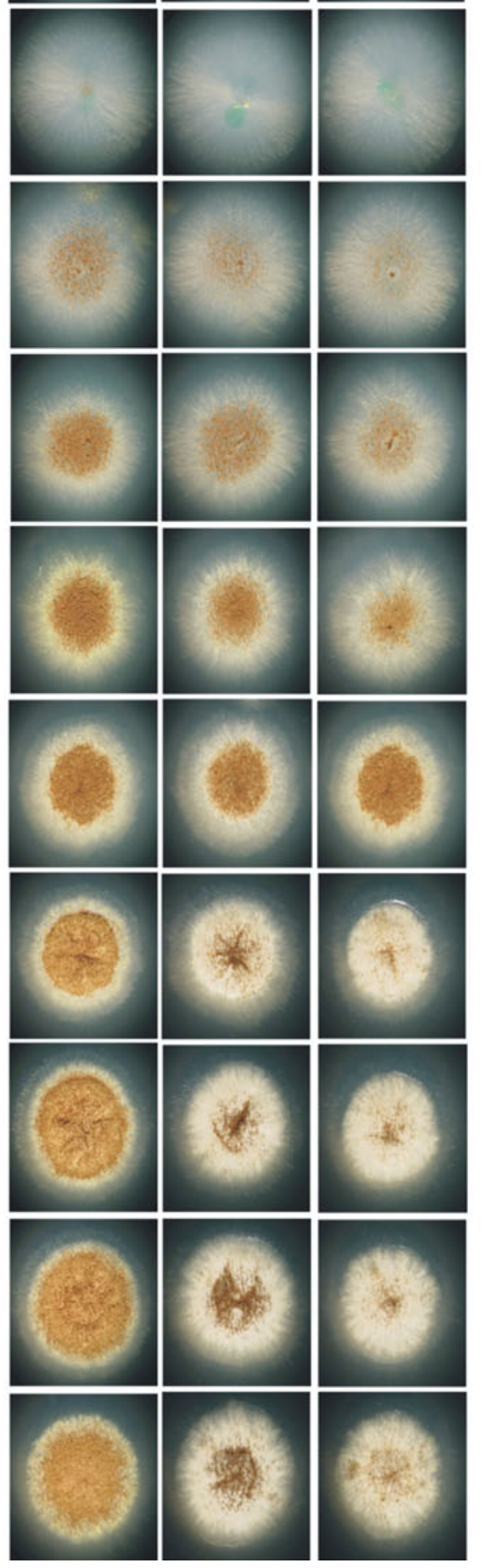
CreA probably overrules induction through AmyR. These data suggests that in A. niger D-glucose or a metabolic product thereof is the inducer of AmyR as was shown previously for A. oryzae (Carlsen and Nielsen 2001). Higher induction of the AmyR-regulated genes on maltose and starch than on D-glucose supports this hypothesis, as growth on these substrates would give a gradual release of D-glucose, resulting in very low steady-state levels. Based on studies in other Aspergilli, differences in the possible inducing compounds may exist between species of this genus. The presence of the recently discovered mal-cluster (Hasegawa et al. 2010; Vongsangnak et al. 2009) in A. oryzae that consists of a putative second maltose-responsive regulator, a maltose transporter and a maltase, suggests that, in this species, at least part of the maltose is transported into the fungal cell. This cluster is also present in Aspergillus flavus, Aspergillus clavatus, Neosartorya fischeri and Aspergillus fumigatus but not in A. niger, A. nidulans and A. terreus (Suppl. Fig. 2), suggesting a different approach to starch utilisation in these two groups of Aspergilli.

The increased hydrolysis of maltose to D-glucose in the amyR multicopy strains is supported by similar morphology of these strains on maltose and on high concentrations of Dglucose. This morphology is likely due to the presence of a high intracellular concentration of D-glucose or a metabolite thereof as it is not observed in the reference strain when it is exposed to high extracellular D-glucose concentrations. This implies that D-glucose transport is upregulated in the multicopy strains, resulting in this higher intracellular concentration of D-glucose or a metabolic product of Dglucose. Analysis of the expression of the three A. niger Dglucose transporters reported previously (Jorgensen et al. 2007; vanKuyk et al. 2004) in the published AmyR micro array data set (Yuan et al. 2008) demonstrated that two of these genes (both encoding high affinity D-glucose transporters) are downregulated in the amyR deletion strain, suggesting control by AmyR. However, considering the presence of multiple putative D-glucose transporters in the $A$. niger genome (Pel et al. 2007), more functional data is needed on these other putative D-glucose transporters before any firm conclusion can be drawn. A similar growth phenotype was observed for strains under secretion stress (Carvalho et al. 2011), but it is unlikely that this can explain our results. It has been well-documented that AmyR-regulated genes are subject to carbon catabolite repression (Tsukagoshi et al. 2001), indicating that an increase in glucose concentration would reduce expression of these genes, resulting in lower protein production and likely also reduced rather than increased secretion stress

In conclusion, our study has shown that the influence of AmyR in A. niger extends beyond starch hydrolysis and suggests a role for D-glucose or a metabolic product thereof as the inducer of the AmyR system in this fungus.

Acknowledgements The authors thank Ec Agbo, Joep Geerlings and Dirk Blom for technical assistance.

Open Access This article is distributed under the terms of the Creative Commons Attribution Noncommercial License which permits any noncommercial use, distribution, and reproduction in any medium, provided the original author(s) and source are credited.

\section{References}

Ademark P, de Vries RP, Hagglund P, Stalbrand H, Visser J (2001) Cloning and characterization of Aspergillus niger genes encoding an $\alpha$-galactosidase and a $\beta$-mannosidase involved in galactomannan degradation. Eur J Biochem 268:2982-2990

Altschul SF, Gish W, Miller W, Myers EW, Lipman DJ (1990) Basic local alignment search tool. J Mol Biol 215:403-410

Andersen MR, Salazar MP, Schaap PJ, van de Vondervoort PJ, Culley D, Thykaer J, Frisvad JC, Nielsen KF, Albang R, Albermann K, Berka RM, Braus GH, Braus-Stromeyer SA, Corrochano LM, Dai Z, van Dijck PW, Hofmann G, Lasure LL, Magnuson JK, Menke H, Meijer M, Meijer SL, Nielsen JB, Nielsen ML, van Ooyen AJ, Pel HJ, Poulsen L, Samson RA, Stam H, Tsang A, van den Brink JM, Atkins A, Aerts A, Shapiro H, Pangilinan J, Salamov A, Lou Y, Lindquist E, Lucas S, Grimwood J, Grigoriev IV, Kubicek CP, Martinez D, van Peij NN, Roubos JA, Nielsen J, Baker SE (2011) Comparative genomics of citric-acid-producing Aspergillus niger ATCC 1015 versus enzyme-producing CBS 513.88. Genome Res 21:885-987

Barton LL, Georgi CE, Lineback DR (1972) Effect of maltose on glucoamylase formation by Aspergillus niger. J Bacteriol 111:771-777

Boel E, Hjort I, Svensson B, Norris F, Norris KE, Fiil NP (1984) Glucoamylases G1 and G2 from Aspergillus niger are synthesized from two different but closely related mRNAs. EMBO J 3:1097-1102

Bos CJ, Debets AJM, Swart K, Huybers A, Kobus G, Slakhorst SM (1988) Genetic analysis and the construction of master strains for assignment of genes to six linkage groups in Aspergillus niger. Curr Genet 14:437-443

Carlsen M, Nielsen J (2001) Influence of carbon source on $\alpha$-amylase production by Aspergillus oryzae. Appl Microbiol Biotechnol 57:346-349

Carvalho ND, Arentshorst M, Kooistra R, Stam H, Sagt CM, van den Hondel CA, Ram AF (2011) Effects of a defective ERAD pathway on growth and heterologous protein production in Aspergillus niger. Appl Microbiol Biotechnol 89:357-373

Coutinho PM, Andersen MR, Kolenova K, vanKuyk PA, Benoit I, Gruben BS, Trejo-Aguilar B, Visser H, van Solingen P, Pakula T, Seiboth B, Battaglia E, Aguilar-Osorio G, de Jong JF, Ohm RA, Aguilar M, Henrissat B, Nielsen J, Stalbrand H, de Vries RP (2009) Postgenomic insights into the plant polysaccharide degradation potential of Aspergillus nidulans and comparison to Aspergillus niger and Aspergillus oryzae. Fungal Genet Biol 46(Suppl 1):S161-S169

Crabtree J, Angiuoli SV, Wortman JR, White OR (2007) Sybil: methods and software for multiple genome comparison and visualization. Methods Mol Biol 408:93-108

de Vries RP, van den Broeck HC, Dekkers E, Manzanares P, de Graaff LH, Visser J (1999a) Differential expression of three $\alpha$ galactosidase genes and a single $\beta$-galactosidase gene from Apergillus niger. Appl Environ Microbiol 65:2453-2460 
de Vries RP, Visser J, de Graaff LH (1999b) CreA modulates the XlnRinduced expression on xylose of Aspergillus niger genes involved in xylan degradation. Res Microbiol 150:281-285

de Vries RP, van de Vondervoort PJI, Hendriks L, van de Belt M, Visser J (2002) Regulation of the $\alpha$-glucuronidase encoding gene (aguA) from Aspergillus niger. Mol Gen Genet 268:96102

de Vries RP, Burgers K, van de Vondervoort PJI, Frisvad JC, Samson RA, Visser J (2004) A new black Aspergillus species, A. vadensis, is a promising host for homologous and heterologous protein production. Appl Environ Microbiol 70:3954-3959

Devereux J, Haeberli P, Smithies O (1984) A comprehensive set of sequence analysis programs for the VAX. Nucl Acids Res 12:387-395

Gielkens MM, Dekkers E, Visser J, de Graaff LH (1999) Two cellobiohydrolase-encoding genes from Aspergillus niger require D-xylose and the xylanolytic transcriptional activator XlnR for their expression. Appl Environ Microbiol 65:4340-4345

Gomi K, Akeno T, Minetoki T, Ozeki K, Kumagai C, Okazaki N, Iimura Y (2000) Molecular cloning and characterization of a transcriptional activator gene, amyR, involved in the amylolytic gene expression in Aspergillus oryzae. Biosci Biotechnol Biochem 64:816-827

Gouka RJ, Punt PJ, van den Hondel CA (1997a) Efficient production of secreted proteins by Aspergillus: progress, limitations and prospects. Appl Microbiol Biotechnol 47:1-11

Gouka RJ, Punt PJ, van den Hondel CA (1997b) Glucoamylase gene fusions alleviate limitations for protein production in Aspergillus awamori at the transcriptional and (post) translational levels. Appl Environ Microbiol 63:488-497

Hasegawa S, Takizawa M, Suyama H, Shintani T, Gomi K (2010) Characterization and expression analysis of a maltose-utilizing (MAL) cluster in Aspergillus oryzae. Fungal Genet Biol 47:1-9

Hasper AA, Dekkers E, van Mil M, van de Vondervoort PJ, de Graaff LH (2002) EglC, a new endoglucanase from Aspergillus niger with major activity towards xyloglucan. Appl Environ Microbiol 68:1556-1560

Jorgensen TR, vanKuyk PA, Poulsen BR, Ruijter GJ, Visser J, Iversen JJ (2007) Glucose uptake and growth of glucose-limited chemostat cultures of Aspergillus niger and a disruptant lacking MstA, a high-affinity glucose transporter. Microbiology 153:19631973

Kato N, Murakoshi Y, Kato M, Kobayashi T, Tsukagoshi N (2002) Isomaltose formed by $\alpha$-glucosidases triggers amylase induction in Aspergillus nidulans. Curr Genet 42:43-50

Kumar V, Ramakrishnan S, Teeri TT, Knowles JKC, Hartley BS (1992) Saccharomyces cerevisiae cells secreting an Aspergillus niger $\beta$-galactosidase grown on whey permeate. Bio/Technology $10: 82-85$

Kusters-van Someren MA, Harmsen JAM, Kester HCM, Visser J (1991) The structure of the Aspergillus niger pelA gene and its expression in Aspergillus niger and Aspergillus nidulans. Curr Genet 20:293-299

Lenouvel F, van de Vondervoort PJ, Visser J (2002) Disruption of the Aspergillus niger $\arg B$ gene: a tool for transformation. Curr Genet 41:425-432

Melchers WJG, Verweij PE, van den Hurk P, van Belkum A, de Pauw BE, Hoogkamp-Korstanje AA, Meis JFGM (1994) General primer-mediated PCR for detection of Aspergillus species. J Clin Microbiol 32:1710-1717

Pedersen H, Beyer M, Nielsen J (2000) Glucoamylase production in batch, chemostat and fed-batch cultivations by an industrial strain of Aspergillus niger. Appl Microbiol Biotechnol 53:272-277
Pel HJ, de Winde JH, Archer DB, Dyer PS, Hofmann G, Schaap PJ, Turner G, de Vries RP, Albang R, Albermann K, Andersen MR, Bendtsen JD, Benen JA, van den Berg M, Breestraat S, Caddick MX, Contreras R, Cornell M, Coutinho PM, Danchin EG, Debets AJ, Dekker P, van Dijck PW, van Dijk A, Dijkhuizen L, Driessen AJ, d'Enfert C, Geysens S, Goosen C, Groot GS, de Groot PW, Guillemette T, Henrissat B, Herweijer M, van den Hombergh JP, van den Hondel CA, van der Heijden RT, van der Kaaij RM, Klis FM, Kools HJ, Kubicek CP, van Kuyk PA, Lauber J, Lu X, van der Maarel MJ, Meulenberg R, Menke H, Mortimer MA, Nielsen J, Oliver SG, Olsthoorn M, Pal K, van Peij NN, Ram AF, Rinas U, Roubos JA, Sagt CM, Schmoll M, Sun J, Ussery D, Varga J, Vervecken W, van de Vondervoort PJ, Wedler H, Wosten HA, Zeng AP, van Ooyen AJ, Visser J, Stam H (2007) Genome sequencing and analysis of the versatile cell factory Aspergillus niger CBS 513.88. Nat Biotechnol 25:221-231

Petersen KL, Lehmbeck J, Christensen T (1999) A new transcriptional activator for amylase genes in Aspergillus. Mol Gen Genet 262:668-676

Punt PJ, Schuren FH, Lehmbeck J, Christensen T, Hjort C, van den Hondel CA (2008) Characterization of the Aspergillus niger prtT, a unique regulator of extracellular protease encoding genes. Fungal Genet Biol 45:1591-1599

Ruijter GJG, Visser J (1997) Carbon repression in aspergilli. FEMS Microbiol Lett 151:103-114

Sambrook J, Fritsch EF, Maniatis T (1989) Molecular cloning-a laboratory manual, 2nd edn. Cold Spring Harbour Laboratory, Cold Spring Harbour

Santerre Henriksen AL, Even S, Muller C, Punt PJ, van den Hondel CA, Nielsen J (1999) Study of the glucoamylase promoter in Aspergillus niger using green fluorescent protein. Microbiology 145:729-734

Schrickx JM, Stouthamer AH, van Verseveld HW (1995) Growth behaviour and glucoamylase production by Aspergillus niger N402 and a glucoamylase overproducing transformant in recycling culture without a nitrogen source. Appl Microbiol Biotechnol 43:109-116

Tani S, Katsuyama Y, Hayashi T, Suzuki H, Kato M, Gomi K, Kobayashi T, Tsukagoshi N (2001) Characterisation of the amyR gene encoding a transcriptional activator for the amylase genes in Aspergillus nidulans. Curr Genet 39:10-15

Tsukagoshi N, Kobayashi T, Kato M (2001) Regulation of the amylolytic and (hemi-) cellulolytic genes in aspergilli. J Gen Appl Microbiol 47:1-19

van Peij N, Gielkens MMC, de Vries RP, Visser J, de Graaff LH (1998a) The transcriptional activator $X \ln R$ regulates both xylanolytic and endoglucanase gene expression in Aspergillus niger. Appl Environ Microbiol 64(10):3615-3619

van Peij NN, Visser J, de Graaff LH (1998b) Isolation and analysis of $x \ln R$, encoding a transcriptional activator co-ordinating xylanolytic expression in Aspergillus niger. Mol Microbiol 27:131-142

vanKuyk PA, Diderich JA, MacCabe AP, Hererro O, Ruijter GJG, Visser J (2004) Aspergillus niger mstA encodes a high-affinity sugar $/ \mathrm{H}^{+}$symporter which is regulated in response to extracellular pH. Biochem J 379:375-383

Vongsangnak W, Salazar M, Hansen K, Nielsen J (2009) Genome-wide analysis of maltose utilization and regulation in aspergilli. Microbiology 155:3893-3902

Yuan XL, van der Kaaij RM, van den Hondel CA, Punt PJ, van der Maarel MJ, Dijkhuizen L, Ram AF (2008) Aspergillus niger genome-wide analysis reveals a large number of novel $\alpha$-glucan acting enzymes with unexpected expression profiles. Mol Genet Genomics 279:545-561 